while in an additional appendix, a four-column tetralingual glossary gives equivalents in those same three languages of 513 German technical terms that have been used to describe properties and reactions (columns 11 and 13 of the directory).

This work certainly contains a valuable tabulation of the commoner organic compounds by melting point, but it is arguable whether it is the vade-mecum for the service of the authors' main target-workers in analytical chemistry. The first edition has been criticized for the brevity with which substances were dismissed and the lack of original references to substantiate the data quoted. The second edition has not remedied the latter deficiency, and the limit in the improvement in coverage may be gauged from the reduction of the average number of items per pair of facing pages from twelve to ten. There are still too few citations of other physical constants important to the analyst and no light absorption data; the number of derivatives quoted is quite inadequate.

In short, although the typography is excellent and the book may be considered a useful adjunct to the analyst's library, the cost is rather prohibitive for the individual. G. F. PHILlips

${ }^{2}$ Kofler, L., and A., Micro Methods for the Determination of Organic Substances and Mixtures of Substances (Verlag Chemie, Weinheim, 1954).

\section{PRINCIPLES AND PRACTICAL APPLICATIONS OF DISTILLATION}

Handbook of Laboratory Distillation

By Erich Krell. Edited by E. C. Lumb. Translated from the second German edition by C. G. Verver. Pp. $x+561$. (Amsterdam, London and New York: Elsevier Publishing Company, 1963.) n.p.

GOR many years to come, Dr. Krell's book will remain A an authoritative work on the principles and practical applications of the distillation method as utilized in the modern laboratory.

It commences with a short historical review which is embellished by diagrammatic representations of stills (curcurbita) and of variously fashioned still-heads (alembics). These more primitive forms of apparatus are shown to become gradually modified with the passage of time to yield the more sophisticated systems developed by Liebig, Jantzen, Young and others. In order to prevent the confusion which can attend the usages of certain phrases in distillation theory, Dr. Krell has provided an excellent glossary which defines exactly those fundamental concepts, for example, countercurrent distillation, height oquivalent to a theoretical plate, plate efficiency, etc. Units are clearly defined, although it is doubtful whether the pressure unit named after Otto Von Guericke $(1 \mathrm{~cm}$ of water pressure $=1$ Ger.) will have much international acceptance.

The application of Raoult's law and of the activity concepts as applied to non-ideal systems are clearly outlined. Comprehensive theoretical chapters deal with $P V T$ relationships, equilibria, theoretical plate, packed column systems, etc., and all these are presented with much attention to the science of practical measurement, for example, the design of ebulliometers, spinning-band columns, molecular distillation, etc. Even the very difficult separation of simple isotopes by the distillation process is dealt with in much theoretical and practical detail, for example, Kuhn's deuterium oxide multi-tube column and Muhlenpfordt's countercurrent method for enriched boron trifluoride. Useful tables of relevant physical data on these substances are presented in the text. Selective methods are described in much detail where changes in the phase equilibria are obtained by using a carrier vapour, by adding other liquids (azeotropic) or by adding salts (solution distillation). Each chapter has a full and adequate bibliography.
The later chapters of the book deal mainly with apparatus, constractional materials, columns, commercial heaters, etc. Considerable attention is directed to the automated process. The diagrams are many and most ably and clearly drawn. Instruments manufactured in the United Kingdom figure very frequently in many of the suggested plants for experimental distillation. A suggested design for a distillation research laboratory is given; even safety measures are not forgotten and receive adequate treatment.

The practical man will find that the detachable nomograms at the end of the book will dispense with the need for much tedious numerical calculation.

This book will undoubtedly become accepted as a standard reference work for chemists, physicists or engineers who are concerned with the applications of the distillation technique either for the purposes of laboratory research, or for development of pilot plant on a semitechnical scale.

D. 'T. LEwIS

\section{ANIMAL SENSES}

\section{The Senses of Animals}

By Dr. L. Harrison Matthews and Maxwell Knight. Pp. $240+20$ plates. (London: Museum Press, Limited, 1963.) $27 s .6 d$.

$T^{0}$ branch of zoology has advanced more rapidly and in a more striking manner, in recent years, than a vast field there is so much going on and so many and complex results emerging from such a wide variety of new techniques that it is becoming increasingly difficult for the non-specialist, and particularly for the school teacher and those concerned with the first year at the university, to keep abreast of the literature sufficiently well to give a balanced, yet not too technical, account of developments to their pupils.

The problem is a serious one; for it would be a great mistake if these new developments were regarded as of such an advanced nature that they should find no place in elementary teaching. It is only by steady incorporation of the results of 'advanced' research into the syllabus of elementary courses that the subject will be kept alive and interesting for the promising pupil. The efforts of those who contribute to magazines of popular science and who provide radio and television programmes have seen to it that many of these intriguing new developments are widely known; only too often, however, the knowledge is serappy and unrelated to the basie groundwork of the subject as a whole. There is therefore great need for books which will ease the task of both teacher and pupil at this level. Moreover, it is most important that the relation of these new developments to field studies be made apparent; for a sadly high proportion of zoology students come to a university without any idea at all of the necessity of at least some field knowledge of animals as part of the groundwork of the subject.

This book sets out to fulfil the need, and it can be said straight away that it does it on the whole extremely well. The first part of the book is written by an able amateur naturalist, the second by a distinguished professional zoologist. Part 1 deals with animal senses in a very general way and aims at pointing out to the student how well an elementary knowledge of animal senses enlightens and revivifies the study of natural history. The treatment is somewhat uneven but it gives a good impression of the role of the various main sense organs in the vertebrates. So far as the invertebrates are concerned, it is comparatively sketchy.

Part 2 is entitled "How Do the Senses Work ?". All in all, it provides an excellent readable and authoritative account of the way the nerves function and of the senses of smell and taste, vision, hearing and touch, as well as 